\title{
APPLICATIONS OF ADULT STEM CELLS IN CRANIO MAXILLOFACIAL REGION- A BOON TO MANKIND
}

\author{
Hema Kanathila', Ashwin Pangi², Bharathi ${ }^{3}$
}

${ }_{1}^{1}$ Reader, Department of Prosthodontics, KLEVK Institute of Dental Sciences, KAHER, Belagavi, Karnataka, India.

${ }^{2}$ Former Reader, Department of Prosthodontics, VPDC, Sangli, Maharashtra, India.

${ }^{3}$ Assistant Professor, Department of Periodontics, Subbaiah Institute of Dental Sciences, Shivamogga, Karnataka, India.

\section{ABSTRACT}

\section{BACKGROUND}

Stem cells are the "master cells" in our body. Stem cells are biological cells that have the capacity to differentiate into specialized cells or produce more stem cells. These cells are studied and can be helpful in the management of various diseases, due to their ability to form connective, neural, bone, muscle and dental tissues. The breakthrough in stem cell research has brought revolutionary changes in the way of treating diseases. This article discusses numerous translational applications of stem cells in craniofacial and maxillofacial area.

\section{KEY WORDS}

Dental Stem Cells, Adult Stem Cells, Regeneration

HOW TO CITE THIS ARTICLE: Kanathila H, Pangi A, Bharathi. Applications of adult stem cells in cranio maxillofacial region- a boon to mankind. J. Evolution Med. Dent. Sci. 2019;8(13):1078-1082, DOI: 10.14260/jemds/2019/238

\section{BACKGROUND}

Numerous studies and researches are carried out for repair and regeneration of defective tissues and lost organs. Regenerative medicine / dentistry has gained momentum over the past decade. The goal of tissue engineering is to stimulate the body either to regenerate tissue on its own or to grow tissue outside the body which can be implanted as natural tissue. Stem cells help by providing a repair approach to the body and help in restoring the adult tissues.

Stem cells are undifferentiated biological cells. They can differentiate into specialised cells and have the capacity to divide by mitosis to produce more stem cells. Stem Cells based on their cell potency and differentiation are divided into unipotent cells, multipotent cells, pluripotent cells and totipotent cells (Figure 1). Basically, there are two broad types of stem cells. They are embryonic/foetal stem cells and adult/postnatal/somatic cells. Embryonic stem cells are obtained from embryos generated by invitro fertilization. Embryonic stem cells can form all the types of cells in the body, as they are pluripotent. They differentiate or mature into the ectoderm, endoderm and mesoderm, that form a human being. But, Immune rejection is seen with these embryonic stem cells. Whereas, the adult stem cells are obtained from umbilical cord blood, umbilical cord, bone marrow, peripheral blood, brain, eyes, liver, muscles, as well as the pulp tissues of teeth. Adult stem cells show limited differentiation into cells types of their tissue origin. They form the cells of the tissue which they belong to. Like, hematopoietic stem cell, which is blood forming stem cell within the bone marrow can form many types of blood cells, but not nerve cells.

'Financial or Other Competing Interest': None.

Submission 06-02-2019, Peer Review 19-03-2019,

Acceptance 25-03-2019, Published 01-04-2019.

Corresponding Author:

Dr. Hema Kanathila,

Reader,

Department of Prosthodontics,

KAHER KLE V K Institute of Dental Sciences,

KLE Academy of Higher Education and Research University

Belagavi, Karnataka, India.

E-mail: hemak_19@yahoo.com

DOI: $10.14260 /$ jemds $/ 2019 / 238$
The adult stem cells formed from patient's own adult stem cells are less likely to get declined or refused by the immune system. Adult cells were genetically reprogrammed to an embryonic stem-like state for maintaining the essential characteristics of embryonic cells, known as induced pluripotent stem cells. They offer great therapeutic potential. As they are formed from a patient's own cells, they can possibly eliminate tissue matching and tissue rejection problems. (Table 1)

The cranio-maxillofacial region consists of many different types of tissues. In this article we discuss the regeneration of defects and diseases occurring in cranio- maxillofacial region which can be divided into maxillo-mandibular bone defects, oral hard tissue, oral soft tissue defects and the temporomandibular problems. The major sources of cells for cranio- maxillofacial regeneration are-

\section{Pluripotent Stem Cells}

a. Embryonic stem cells

b. Induced pluripotent stem cells (iPSC s)

2. Adult Stem Cells

a. Bone marrow

b. Adipose tissue

c. Stem cells from oral and maxillofacial region which include- Dental pulp stem cells (DPSC s), Stem cells from exfoliated deciduous teeth, periodontal ligament stem cells (PDLSC s), dental follicle progenitor cells (DFPC s).

Because of the medical and legal issues, application of stem cells of embryonic origin in clinical practices is not preferred. Despite the advantages of induced pluripotent stem (IPS) cells over embryonic stem cells, certain barriers like low reprogramming efficiency, concerns regarding oncogenicity and teratoma formation limit their clinical utility.

In this article, we have reviewed on the adult stem cells which are helpful in the management of cranio-maxillofacial defects. Among the adult stem cells used in the craniomaxillofacial defects, dental stem cells have a lot of advantages. They are readily accessible, easy and least invasive approach to secure and reasonable alternative for obtaining stem cells, show good interaction with scaffolds, high proliferative and multi differentiation potential and can be cryopreserved for more time period. 
Stem cells can be easily obtained from deciduous teeth and third molars after exfoliation or removal of impacted teeth. They can be stored for treatment of future diseases by using regenerative techniques. The pulp of deciduous teeth has been studied extensively and found to contain chondrocytes, osteoblasts, adipocytes and mesenchymal stem cells. All of these types of cells have great therapeutic potential.

\section{Craniofacial Regeneration}

Craniofacial problems are difficult to be corrected surgically, which often turns out to be multistage and multidisciplinary approach. Finally results turn out to be unpredictable and unsatisfactory. The advances in regenerative science help in replacing the missing structures with healthy regenerated tissue.

Stem cells can be helpful in the regeneration of bone and to treat large craniofacial defects due to trauma, tumour resection and cyst enucleation. Different cell types are used in repairing large and complex craniofacial defects. In the craniofacial region, bone marrow mesenchymal stem cells (BMMSC), dental pulp stem cells (DPSCs), periodontal ligament stem cells (PDLSCs), and stem cells from human exfoliated deciduous (SHED) teeth have been identified as potential ones, which have regenerative capacity. Stem cells from oral and maxillofacial region along with bone marrow stem cells can be useful in correcting larger defects. ${ }^{1}$

Bone marrow mesenchymal stem cells have been reported to be capable of multipotential differentiation and have been applied in the repair of craniofacial defect. Several studies have shown their capability as osteoblastic precursors in the reconstruction of detects. ${ }^{2,3,4}$ Gronthos et al in their invitro study on adult BMMSC $\mathrm{s}$ suggested that BMMSC $s$, when cultured in the presence of dexamethasone, inorganic phosphate and vitamin c, can induce formation of osteoblast like cells and calcified nodules. ${ }^{5}$ Kon et al and Mankani et al in their animal study, demonstrated the repair of calvarial and long bone defects to be successful.6,7

Clinical experiments have been carried out, in order to repair the bony defects in mandible by autologous BMMSC s. In a study by Warnke et al, patient showed enhanced mastication and aesthetics after seeding autologous BMMSCs onto mandible scaffolds(custom-made) made of titanium and bone mineral blocks containing BMP7, which was kept for 7 weeks beneath patient's skin and later transplanted into the patient's mouth to repair the mandibular defect. ${ }^{8}$ Mesenchymal stem cells obtained from umbilical cord blood with poly-lactic co-glycolic acid (PLGA) implants, have shown successful healing of large alveolar cleft defects in animal study. ${ }^{9}$ Mesenchymal stem cells isolated from orofacial tissues using alginate based hydrogels also have been applied in craniofacial tissue engineering. ${ }^{10} \mathrm{~A}$ recent clinical study demonstrated that CD90+ osteoblastic BMSCs and CD14+ monocytes and macrophages placed onto a b-tricalcium phosphate (b-TCP) scaffold gave a successful treatment outcome for severe maxillary deficiency patients. ${ }^{11}$ DPSCs can be used for rapid regeneration of craniofacial bone and alveolar bone, as they show more osteogenic potential than bone marrow stem cells. Also, DPSCs are considered as a useful source for tissue-engineered bone around dental implants.
Adipose-derived stem cells (ADSCs) also present a good alternative to BMSCs. ADSCs are harvested or isolated from lipectomy or liposuction aspirates. Adipose tissue can be obtained by less invasive methods and in larger quantities than bone marrow cells. In a study by Hicok et al, the ability of ADSCs to form osteoid matrix in vivo was determined and proved it to be useful for bone repair and regeneration. ${ }^{12}$ ADSCs have shown osteogenic potential similar to BMSCs, with some subpopulations showing improved osteoblast differentiation. ${ }^{13}$

Eventhough poorly studied, urine derived stem cells (USC) have attained a great attention in the field of tissue engineering. USCs are considered to be similar to ADSCs with their in vitro ability of osteogenic differentiation. Guan et al in their in vitro study, have suggested their applicability to bone regeneration. ${ }^{14}$

\section{Tooth Regeneration}

A tooth constitutes an important role in all major oral functions. Loosing milk tooth is a part of childhood, but loosing permanent teeth due to caries, periodontal problems or trauma requires attention and solution. Dental stem cells could create a revolution for patients who face dental problems leading to tooth loss, as dental stem cell acts as a universal cell which can be morphed to different types of tissues in oral cavity. Tooth regeneration includes regenerating multiple hard and soft tissues in harmony which presents a major challenge. Hence dental stem cell application in regenerative field is widely studied.

For regeneration of a tooth in humans, two types of stem cells are required. They are epithelial and mesenchymal stem cells. ${ }^{15}$ Epithelial and mesenchymal stem cells from embryo showed the ability for tooth formation, in animals. The types of human adult mesenchymal stem cells (HAMSCs) which can be used for tooth regeneration include dental mesenchymal stem cells and bone marrow derived mesenchymal stem cells. ${ }^{16,17}$ Both of these have odontogenic as well as osteogenic potential. Dental mesenchymal stem cells, such as Stem Cells from the Apical Papilla (SCAP), Dental Pulp Stem Cells (DPSCs), Stem Cells from Human Exfoliated Deciduous teeth (SHED), Periodontal Ligament Stem Cells (PDLSCs) and Dental Follicle Precursor Cells (DFPCs) have gained more attention for tooth generation. Because they appear to show odontogenic rather than osteogenic development.18 When reunification of dental epithelial and mesenchymal tissues takes place it leads to the formation of tooth, in vitro as well as in vivo. Nakao et al in their study, engineered teeth ectopically followed by transplantation in orthotopic site in a mouse jaw. ${ }^{15} \mathrm{Kim}$ et al attempted to regenerate alveolar bone, pulp, cementum, PDL and dentine of mandibular molars by a feasible method using cell homing, in animal model. And this study concluded cell homing as a method to be considered for tooth regeneration in future. ${ }^{19}$

\section{Enamel and Dentin- Pulp Complex Regeneration}

Enamel is the outermost covering of teeth which cannot regenerate by itself. Conventional treatment modalities use artificial materials to restore the lost enamel substance which can never be same-like natural enamel. Studies in this area, by understanding the protein interactions and isolation of post-natal stem cells from various sources in the mouth along with scaffolds, helps in enamel regeneration. Harada et al 
mentioned the identification of dental epithelial stem cells in the rodent incisor. Even though, dental epithelial stem cells contribute in the regeneration of ameloblasts in rodents, these cells differ from human teeth, as dental epithelial stem cells are lost after eruption of the tooth. 20

Regenerative dentin formation has been shown in a model using DPSCs with dentin matrix protein 1 (DMP1). Reparative dentin formation was noted when stem cells were used with recombinant human bone morphogenetic protein 2 (BMP 2) in studies on animal specimens. ${ }^{21}$

Regeneration of the pulp inside the decayed and destructed tooth can be a reviving application of stem cell therapy in the field of dentistry. Stem cells procured from the pulp of third molar can be used to regenerate the pulp of grossly traumatised tooth, thus declining the need for endodontic treatment of such tooth. SHED as well as DPSCs are capable of forming or generating tissues similar to tooth pulp under optimal conditions. Pulp tissue with good blood supply and nerve supply was noticed after autologous transplantation of DPSCs with stromal cell-derived factor 1(SDF-1).22,23 Gronthos et al in their animal studies demonstrated that pulp stem cells (DPSCs) were able to form dentin and related pulp tissue. ${ }^{24}$ Various in vitro studies have tried the formation of teeth by application of stem cells from tooth pulp with proper scaffold materials. Inductive morphogenes, stem cells, scaffold have been identified as three key elements necessary for tooth regeneration.

Scaffolds present as a 3-D framework for cells and help as an extracellular matrix for a long time. The first scaffold material used for tooth tissue engineering was a copolymer of Polyglycolic Acid (PGA) or Poly-L-Lactic acid (PLLA) and Poly (lactic-co-glycolic acid) (PLGA), which was successful. Scaffolds help in cell migration and proliferation. ${ }^{25}$ Buurma et al in their study in immunocompromised mice, found that pulp cells placed inside PGA and implanted into subcutaneous space was capable of forming extracellular matrix and new blood vessels in vivo in 3 weeks after the implantation. ${ }^{26}$

PLLA has been used in many studies, and tissue similar to that of tooth pulp has been formed, where tooth pulp stem cells are seeded onto the PLLA scaffolds. ${ }^{27}$

\section{Periodontal Regeneration}

Periodontal regeneration requires multipotential stem cell, as periodontium included gingival, periodontal ligament, cementum and the surrounding bone. The Periodontal ligament is unique because it is the only soft tissue connecting two distinct hard tissues. The periodontal ligament is a specialized connective tissue, derived from dental follicle and originated from neural crest cells. It has been reported that PDLSCs could differentiate into cells that can colonize and grow on biocompatible scaffold. This suggested an easy and efficient source of stem cells for bone tissue engineering in the field regenerative dentistry. Because of their capacity to differentiate into osteoblasts, cementoblasts, and fibroblasts, PDLCs were the first stem cells for periodontal tissue engineering. As these cells have the potential to form collagen fibers and generate cementum/PDL-like structures in vivo, they act as good sources for periodontal tissue reconstruction.

Park J Y et al carried out a study in beagle dogs comparing PDLSCs with stem cells obtained from other dental sources and they concluded that PDLSCs as the most predictable in carrying out regeneration. ${ }^{28,29}$ Hynes et al, concluded that PDLSCs presented the greatest capacity for periodontal regeneration than other stem cells like DPSCs, BM-SCs, periapical follicular stem cells.30 Kawaguchi et al in their study transplanted exvivo expanded bone marrow MSCs into periodontal defects and noted successful repair of the defective periodontal tissue, after a month.24,31 Duan, et al in their study, used induced pluripotent stem cells along with Emdogain in periodontal fenestration defect models resulting in the total periodontal regeneration. ${ }^{32}$

\section{Cleft Lip and Palate}

Cleft lip and palate is a common malformation with an incidence of between one and two in 1000 live births. This congenital defect occurs due to improper fusion during embryogenesis. This complex defect and the prolonged rehabilitation period after surgery, affects the family psychologically and economically.

Stem cells obtained from craniofacial tissues give a new ray of hope in cleft lip and palate patients. Literature review shows that both undifferentiated adipose tissue stem cells and bone marrow derived mesenchymal stem cells have osteogenic, chondrogenic and lipogenic differentiation potential which can help in defect repair in reconstructive surgeries. Alamoudi et al in their review, concluded that, further studies on stem cell types, scaffolds and growth factors will help to manipulate bone and soft tissue regeneration and put forward more therapeutic options for cleft lip and palate patients in future. ${ }^{33}$

\section{Regeneration of Oral Mucosa}

Oral mucosa shows extremely good healing with minimal scar formation and accelerated healing time as well as good regenerative characteristics. With increasing rates of oral cancer, there is a need for regenerative therapies related to oral tissues. Garz'on et al in their study have suggested method of oral mucosal regeneration using MSCs placed on stroma containing fibrin and oral mucosa fibroblasts to induce epithelial differentiation. This was later grafted onto a $2.5 \mathrm{~cm}^{2}$ skin excision on the dorsal surface of immunodeficient athymic mice. This study showed the presence of epithelial keratinocytes and epithelial layers consisting of basal, spinosum, granulosum, and corneum cell layers. This has put forward a good option for patients who require large areas of regeneration of oral mucosa. 34

\section{Temporomandibular Joint Regeneration-}

The temporomandibular joint (TMJ) is formed by bony as well as cartilaginous parts. Temporomandibular disorders (TMD) represent a group of muscular, skeletal and neuromuscular conditions involving the temporomandibular joint (TMJ), masticatory muscles and other related structures. Various animal studies on TMJ have been conducted. In a work conducted by Alhadlaq and Mao, new bone formation resembling human condyle in shape and dimensions were seen by using bone marrow MSCs from long bone marrow. ${ }^{35,36} \mathrm{Wu}$ et al demonstrated the utility of TMJ-derived synovial MSCs in repairing the TMJ disc. ${ }^{37}$ 


\begin{tabular}{|c|c|c|}
\hline Cell Potency & $\begin{array}{c}\text { Differentiation } \\
\text { Capacity }\end{array}$ & Example \\
\hline $\begin{array}{c}\text { Totipotent } \\
\text { Cells }\end{array}$ & $\begin{array}{c}\text { Can form all cell types in } \\
\text { a body, also the } \\
\text { extraembryonic or } \\
\text { placental cells. }\end{array}$ & $\begin{array}{c}\text { Embryonic cells } \\
\text { within the first } \\
\text { couple of cell } \\
\text { divisions after } \\
\text { fertilization, }\end{array}$ \\
\hline $\begin{array}{c}\text { Pluripotent } \\
\text { Cells }\end{array}$ & $\begin{array}{c}\text { Can give rise to all of the } \\
\text { cell types that make up } \\
\text { the body }\end{array}$ & $\begin{array}{c}\text { Embryonic stem } \\
\text { cells, induced } \\
\text { pluripotent cells } \\
\text { (IPS cells) }\end{array}$ \\
\hline $\begin{array}{c}\text { Multipotent } \\
\text { Cells }\end{array}$ & $\begin{array}{c}\text { Can develop into more } \\
\text { than one cell type. } \\
\text { They are more limited } \\
\text { than pluripotent cells }\end{array}$ & $\begin{array}{c}\text { Adult stem cells and } \\
\text { cord blood stem } \\
\text { cells. }\end{array}$ \\
\hline $\begin{array}{c}\text { Unipotent } \\
\text { Cells }\end{array}$ & $\begin{array}{c}\text { Can differentiate into } \\
\text { only one cell type. Least } \\
\text { potent }\end{array}$ & Muscle stem cells \\
\hline \multicolumn{2}{|c|}{ Table 1. Cell Potency and Differentiation } \\
\hline \multicolumn{3}{|c|}{}
\end{tabular}

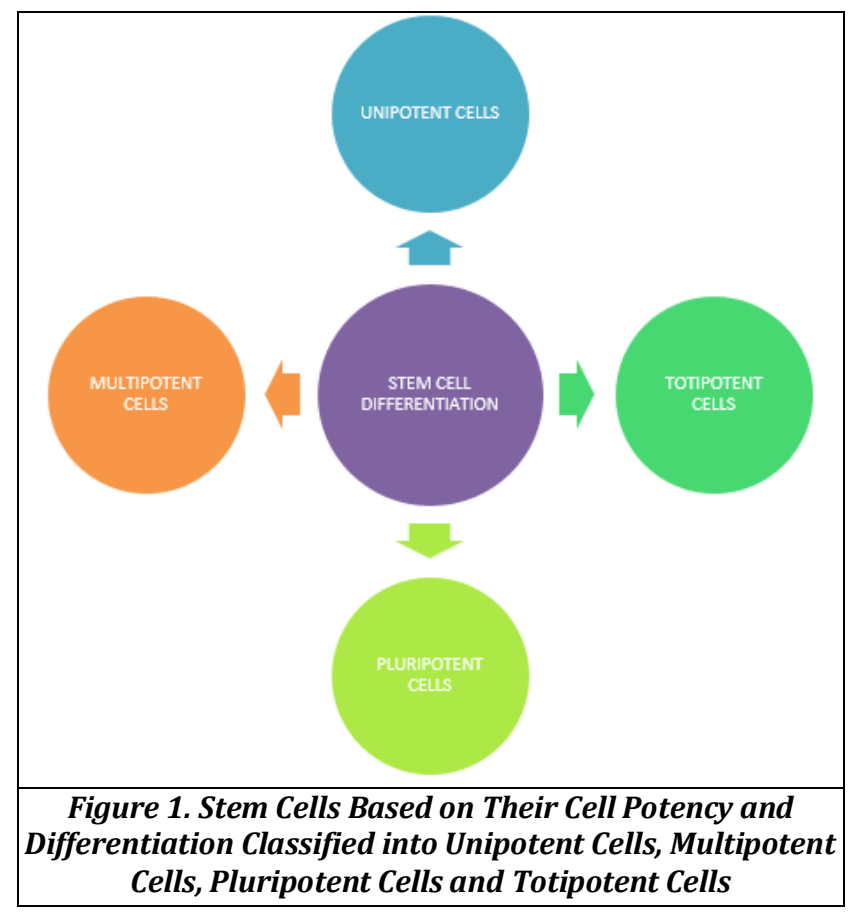

\section{CONCLUSION}

Research in the area of stem cells has brought lot of development in tissue engineering of tooth related issues. If stem cells are applied successfully in humans, it can give a clinical approach to replace dental implants in future. A new era of dentistry can be formed by dental stem cells in future by replacing dental implants and bridges, which at present replace lost teeth. Understanding the biological concepts, together with vast number of researches in this field has helped in finding solutions to biological problems.

\section{REFERENCES}

[1] Sunil P, Manikandhan R, Muthu M, et al. Stem cell therapy in oral and maxillofacial region: an overview. J Oral Maxillofac Pathol 2012;16(1):58-63.

[2] Ueda M, Yamada Y, Ozawa R, et al. Clinical case reports of injectable tissue-engineered bone for alveolar augmentation with simultaneous implant placement. Int J Periodontics Restor Dent 2005;25(2):129-37.
[3] Levi B, James AW, Nelson ER, et al. Human adipose derived stromal cells heal critical size mouse calvarial defects. PLoS One 2010;5(6):e11177.

[4] Chung MT, Liu C, Hyun JS, et al. CD90 (Thy-1)-positive selection enhances osteogenic capacity of human adipose derived stromal cells. Tissue Eng Part A 2012;19(7-8):989-97.

[5] Gronthos S, Graves SE, Ohta S, et al. The STRO-1+ fraction of adult human bone marrow contains the osteogenic precursors. Blood 1994;84(12):4164-73.

[6] Kon E, Muraglia A, Corsi A, et al. Autologous bone marrow stromal cells loaded onto porous hydroxyapatite ceramic accelerate bone repair in critical-size defects of sheep long bones. J Biomed Mater Res 2000;49(3):328-37.

[7] Mankani MH, Krebsbach PH, Satomura K, et al. Pedicled bone flap formation using transplanted bone marrow stromal cells. Arch Surg 2001;136(3):263-70.

[8] Warnke PH, Springer IN, Wiltfang J, et al. Growth and transplantation of a custom vascularised bone graft in a man. Lancet 2004;364(9436):766-70.

[9] Caballero M, Morse JC, Halevi AE, et al. Juvenile swine surgical alveolar cleft model to test novel autologous stem cell therapies. Tissue Eng Part C Methods 2015;21(9):898-900.

[10] Ansari S, Seagroves JT, Chen C, et al. Dental and orofacial mesenchymal stem cells in craniofacial regenration: the prosthodontist's point of view. J Prosthet Dent 2017;118(4):455-61.

[11] Kaigler D, Avila-Ortiz G, Travan S, et al. Bone engineering of maxillary sinus bone deficiencies using enriched CD90+ stem cell therapy: a randomized clinical trial. J Bone Miner Res 2015;30(7):1206-16.

[12] Hicok KC, Du Laney TV, Zhou YS, et al. Human adiposederived adult stem cells produce osteoid in vivo. Tissue Eng 2004;10(3-4):371-80.

[13] Liao YH, Chang YH, Sung LY, et al. Osteogenic differentiation of adipose-derived stem cells and calvarial defect repair using baculovirus-mediated coexpression of BMP-2 and miR-148b. Biomaterials 2014;35(18):4901-10.

[14] Guan J, Zhang J, Zhu Z, et al. Bone morphogenetic protein 2 gene transduction enhances the osteogenic potential of human urine-derived stem cells. Stem Cell Res Ther 2015;6:5.

[15] Nakao K, Morita R, Saji Y, et al. The development of a bioengineered organ germ method. Nat Methods 2007;4(3):227-30.

[16] Huang GT, Gronthos S, Shi S. Mesenchymal stem cells derived from dental tissues vs. those from other sources: their biology and role in regenerative medicine. J Dent Res 2009;88(9):792-806.

[17] Arakaki M, Ishikawa M, Nakamura T, et al. Role of epithelial-stem cell interactions during dental cell differentiation. J Biol Chem 2012;287(13):10590-601.

[18] Xiao L. Human stem cells and tooth regeneration. J Stem Cell Res Ther 2012;2:3.

[19] Kim K, Lee CH, Kim BK, et al. Anatomically shaped tooth and periodontal regeneration by cell homing. J Dent Res 2010;89(8):842-7. 
[20] Otsu E, Kumakami-Sakano M, Harada H, et al. Stem cell sources for tooth regeneration: current status and future prospects. Front Physiol 2014;5:36.

[21] Alsanea R, Ravindran S, Fayad MI, et al. Biomimetic approach to perforation repair using dental pulp stem cells and dentin matrix protein $1 . \mathrm{J}$ Endod 2011;37(8):1092-97.

[22] Nakashima M, Iohara K. Regeneration of dental pulp by stem cells. Adv Dent Res 2011;23(3):313-9.

[23] Ishizaka R, Hayashi Y, Iohara K, et al. Stimulation of angiogenesis, neurogenesis and regeneration by side population cells from dental pulp. Biomaterials 2013;34(8):1888-97.

[24] Singh H, Bhaskar DJ, Rehman R, et al. Stem cells: an emerging future in dentistry. International Journal of Advanced Health Sciences 2014;1(2):17-23.

[25] Sanchez-Lara PA, Warburton D. Impact of stem cells in craniofacial regenerative medicine. Front Physiol 2012;3:188.

[26] Buurma B, Rutherford R, Gu K. Transplantation of human pulpal and gingival fibroblasts attached to synthetic scaffolds. Eur J Oral Sci 1999;107(4):282-9.

[27] Demarco FF, Casagrande L, Zhang Z, et al. Effects of morphogen and scaffold porogen on the differentiation of dental pulp stem cells. J Endod 2010;36(11):1805-11.

[28] Park JY, Jeon SH, Choung PH. Efficacy of periodontal stem cell transplantation in the treatment of advanced periodontitis. Cell Transplant 2011;20(2):271-85.

[29] Thomas GV, Thomas NG, John S, et al. The scope of stem cells in periodontal regeneration. J Dent Oral Disord Ther 2015;3(2):1-9.
[30] Hynes K, Menicanin D, Gronthos S, et al. Clinical utility of stem cells for periodontal regeneration. Periodontol 2000 2012;59(1):203-27.

[31] Kawaguchi H, Hirachi A, Hasegawa N, et al. Enhancement of periodontal tissue regeneration by transplantation of bone marrow mesenchymal stem cells. J Periodontol 2004;75(9):1281-7.

[32] Duan X, Tu Q, Zhang J, et al. Application of induced pluripotent stem (iPS) cells in periodontal tissue regeneration. J Cell Physiol 2011;226(1):150-7.

[33] Alamoudi N, Reem A, El-Ashiry E, et al. Bone marrow and adipose tissue derived mesenchymal stem cells in regeneration of cleft lip and alveolus: a review literature. J Oral Hyg Health 2017;5:1.

[34] Garzón I, Miyake J, González-Andrades M, et al. Wharton's jelly stem cells: a novel cell source for oral mucosa and skin epithelia regeneration. Stem Cells Transl Med 2013;2(8):625-32.

[35] Alhadlaq A, Mao JJ. Tissue-engineered neogenesis of human-shaped mandibular condyle from rat mesenchymal stem cells. J Dent Res 2003;82(12):9516.

[36] Alhadlaq A, Mao JJ. Mesenchymal stem cells: isolation and therapeutics. Stem Cells Dev 2004;13(4):436-48.

[37] Wu Y, Gong Z, Li J, et al. The pilot study of fibrin with temporomandibular joint derived synovial stem cells in repairing TMJ disc perforation. Biomed Research International 2014;2014:1-10. 